\title{
GESTIÓN AMBIENTAL Y GOBERNANZA EN LOS MUNICIPIOS DEL VALLE DEL CAUCA
}

\author{
Environmental Management and Governance \\ In Municipalities of Valle del Cauca
}

\author{
ALEXANDER BURITICA-CASANOVA ${ }^{1}$, FABIO ARIAS-ARBELAEZ ${ }^{2}$ \\ ${ }^{1}$ Economista. Asistente de investigación en CIAT. ${ }^{2}$ Ph.D. en Desarrollo Sustentable. \\ Profesor Universidad del Valle, Facultad de Ciencias Sociales y Económicas.
}

E-mail: a.buritica@cgiar.org

fabio.arias@correounivalle.edu.co

Recibido: 13 de Octubre de 2015

Aceptado: 26 de Octubre de 2015

\section{Resumen}

Esta investigación analiza la gestión ambiental en los municipios del Valle del Cauca, Colombia. El estudio parte de una pregunta exploratoria ¿Cómo responden a la gestión ambiental los municipios del Valle del Cauca? Con base en los informes ambientales de la Contraloría Departamental del Plan de desarrollo se observa que la gestión ambiental en los municipios del Valle del Cauca se presenta en forma desigual. Por lo cual, la pregunta principal de investigación es ¿Por qué los municipios del Valle del Cauca responden de manera desigual en su gestión ambiental? Para responder a la pregunta se usa un enfoque metodológico de tipo descriptivo y analítico. Basado en el análisis de seis dimensiones de gobernanza se encuentra que la estabilidad política y ausencia de violencia, efectividad gubernamental y control de la corrupción permiten explicar una mayor o menor respuesta por parte de los municipios a la Gestión Ambiental.

Palabras claves: Gestión Ambiental, Clúster Análisis, Inversión Ambiental Municipal.

\section{Abstract}

This research analyzes the environmental management in the municipalities of Valle del Cauca, Colombia. The study beginning with an exploratory question: how they respond to environmental management in the municipalities of Valle del Cauca? Environmental reports by the Departmental Comptroller of the Plan of Development that environmental found out that the environmental management is different among that different municipalities. Therefore, the principal research question is why the municipalities of Valle del Cauca respond to environmental management unevenly? To answer the question a methodological approach to descriptive and analytical type is used. Based on the analysis of the six dimensions of governance it is found that Political Stability and Absence of Violence, Government Effectiveness and Control of Corruption can explain more or less the different response from the municipalities for environmental management.

Keywords: Environmental management, Cluster analysis, Municipal Environmental Investment. 


\section{INTRODUCCIÓN}

La gestión ambiental es un asunto de carácter colectivo, que responde al "¿Cómo?" y el "¿Qué?" diferentes actores se organizan para lograr un adecuado uso de los recursos naturales reduciendo el deterioro del medio ambiente. La gestión ambiental es parte sustancial de la gestión pública, y esta debe entenderse como un proceso social y político continuo en el que intervienen diversos actores, en el que se definen, formulan y ejecutan un conjunto de acciones que tienen como finalidad el desarrollo sostenible de un territorio y el mejoramiento de la calidad de vida de la población (González 2001).

En la Constitución Política de Colombia del año 1991 se incorpora en su articulado el tema ambiental, fijando responsabilidades ambientales al Estado y la sociedad civil. Prueba de ello se encuentra en leyes que establecen la obligatoriedad de incorporar programas y proyectos ambientales en los planes de desarrollo además de criterios y mecanismos para la participación de las comunidades en los procesos de planeación de las entidades territoriales (Colombia 1994 art.1). Se establece que es en el municipio donde se vuelve ineludible materializar instrumentos de planificación, dotarlos con las herramientas, técnicas, jurídicas y administrativas necesarias para la generación de planes locales que brinden una orientación más estratégica y real de su gestión ambiental. Dado que es en el nivel local donde se manifiesta claramente la oferta y las restricciones de uso de los recursos naturales, el municipio es el actor fundamental en la gestión ambiental dentro del estado.

El estudio se inicia con la pregunta exploratoria ¿Cómo responden a la gestión ambiental los municipios del Valle del Cauca? La hipótesis es que las habilidades o atributos socioeconómicos y de gestión con las que cuentan diferentes actores del municipio inciden en cómo se responde a la Gestión del Medio Ambiente. La opción para abordar el análisis de la gestión ambiental y sus resultados, se presenta en el concepto de gobernanza. Este concepto permite explicar la habilidad del municipio resolviendo asuntos colectivos, en este caso la gestión ambiental. Como lo indica Wallace \& Wallace (2000), la gobernanza se ha transformado en una actividad de múltiples niveles, intricadamente institucionalizada y especialmente diversa, al tiempo que la

\footnotetext{
${ }^{1}$ La ley 136 de 1994 establece que los municipios en Colombia se clasificaran, de acuerdo a su población y sus recursos fiscales como indicadores de sus condiciones socioeconómicas en siete categorías: categoría especial, primera, segunda, tercera, cuarta, quinta y sexta categoría.
}

2 Este es un índice de aptitud de las tierras para actividades agropecuarias. El índice de aptitud comprende siete categorías dependiendo de las representación, la lealtad y la identidad siguen estando empecinadamente ancladas en las comunidades étnicas, regionales y nacionales.

\section{MATERIALES}

\section{Zona de estudio}

Esta investigación aborda la gestión ambiental en los municipios del Valle del Cauca, debido a su gran variedad municipal1 ${ }^{1}$. El 74\% de los municipios del Departamento son de tamaño pequeño (categoría 6) y el $26 \%$ restante se reparte en municipios de tamaños intermedios, municipios de primera categoría y categoría Especial. Está ubicado en el suroccidente del país, limita al norte con los departamentos de Chocó y Risaralda, al oriente con Quindío y Tolima, al sur con Cauca y al occidente con el Océano Pacífico. Actualmente está dividido en 42 municipios (Figura 1).

Por otro lado, el Valle del Cauca permite observar diferentes aspectos físicos y naturales en temas como disponibilidad de agua, erosión y aptitud ${ }^{2}$ del suelo dentro de sus municipios. En la Figura 2, se muestra el comportamiento de la disponibilidad de agua, erosión y aptitud del suelo para todos los municipios del Valle. Se observa que existen diferencias marcadas para todos los municipios en erosión y aptitud del suelo. Además, de las diferencias al interior de cada categoría municipal, como por ejemplo en los municipios: La cumbre, Rio frio, Dagua, Alcalá y Ulloa (Categoría $6^{3}$ ) que presentan grandes diferencias en el índice de disponibilidad de agua.

\section{Gestión Ambiental en el Valle del Cauca}

El estudio parte de una pregunta exploratoria ¿cómo responden a la gestión ambiental los municipios del Valle del Cauca? Para lo cual se analiza la gestión ambiental en el marco de los informes Ambientales por parte de la Contraloría Departamental del Plan de desarrollo. Dado que conforme a lo establecido en la Constitución Política ${ }^{4}$, el Plan de desarrollo se define como un instrumento para la gestión ambiental (Corporación Autónoma Regional del Valle del Cauca 2002).

posibilidades o limitaciones para actividades agropecuarias según condiciones como topografía, drenaje, clima y otros. ${ }^{3}$ Municipios con población igual o inferior a 10,000 habitantes y con ingresos
anuales no superiores a 15,000 salarios mínimos vigentes.

${ }^{4}$ Artículo 39 de la ley 152 de 1994, Artículo 9 de la Ley 330 de 1993. 
Ambiente y Sostenibilidad 2015 (5): 78-96

Revista del Doctorado Interinstitucional en Ciencias Ambientales

ISSN: 2339-3122

Digital

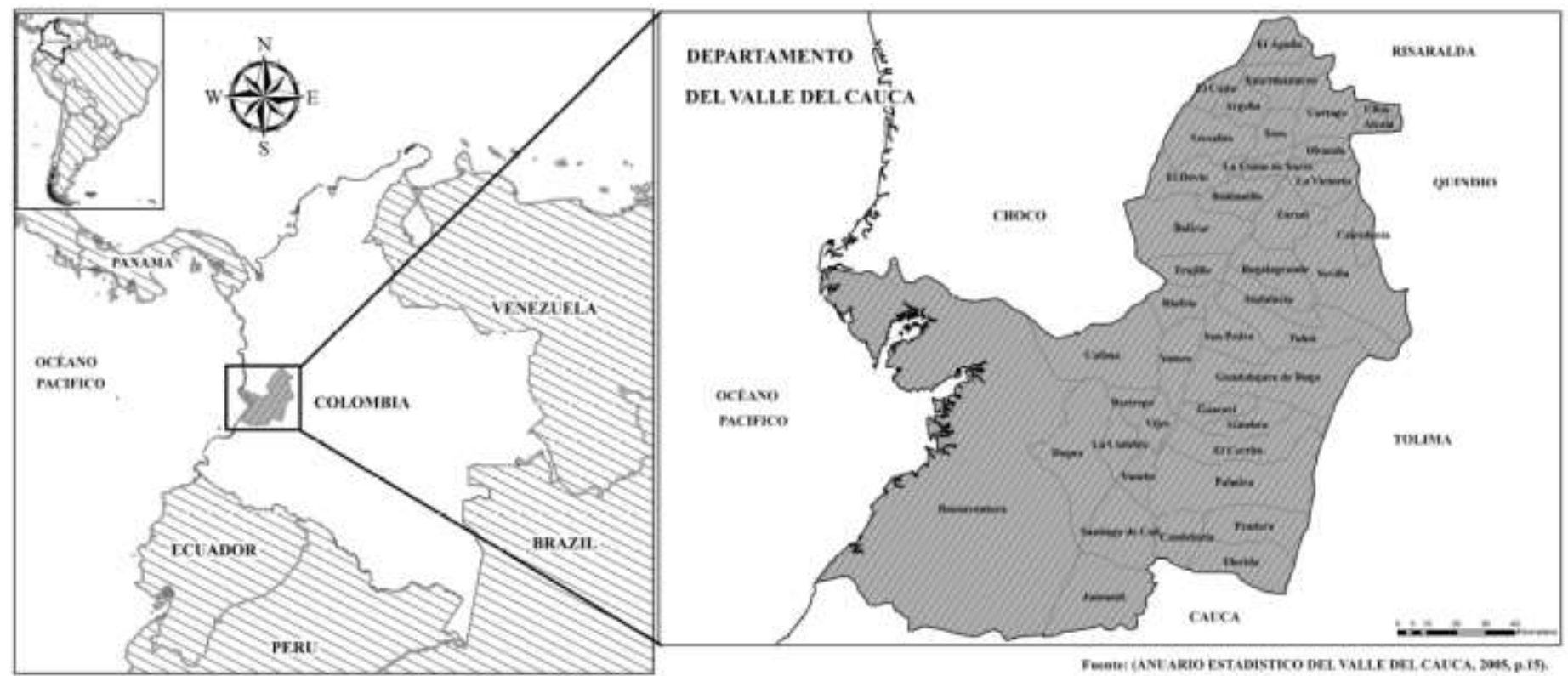

Figura 1. Mapa división política y administrativa Valle del Cauca. Fuente: Anuario estadístico del Valle del Cauca, 2005.

Los informes ambientales por parte de la controlaría evalúan la gestión municipal y departamental, en el marco de los planes de desarrollo. Dado que es en el plan de desarrollo donde se consigna los objetivos, metas y estrategias territoriales y sectoriales de la acción del estado. Los planes de desarrollo son conformados y coordinados desde las dependencias de la administración municipal ${ }^{5}$ de cada municipio. Estos tienen una formulación de 4 años, constituidos por una parte general, que contempla las líneas, objetivos, componentes y metas de los proyectos del plan; y con una parte presupuestal, también denominada plan de inversiones, que determina como se invertirán los recursos durante la ejecución del plan (Ministerio de Medio Ambiente 2002).

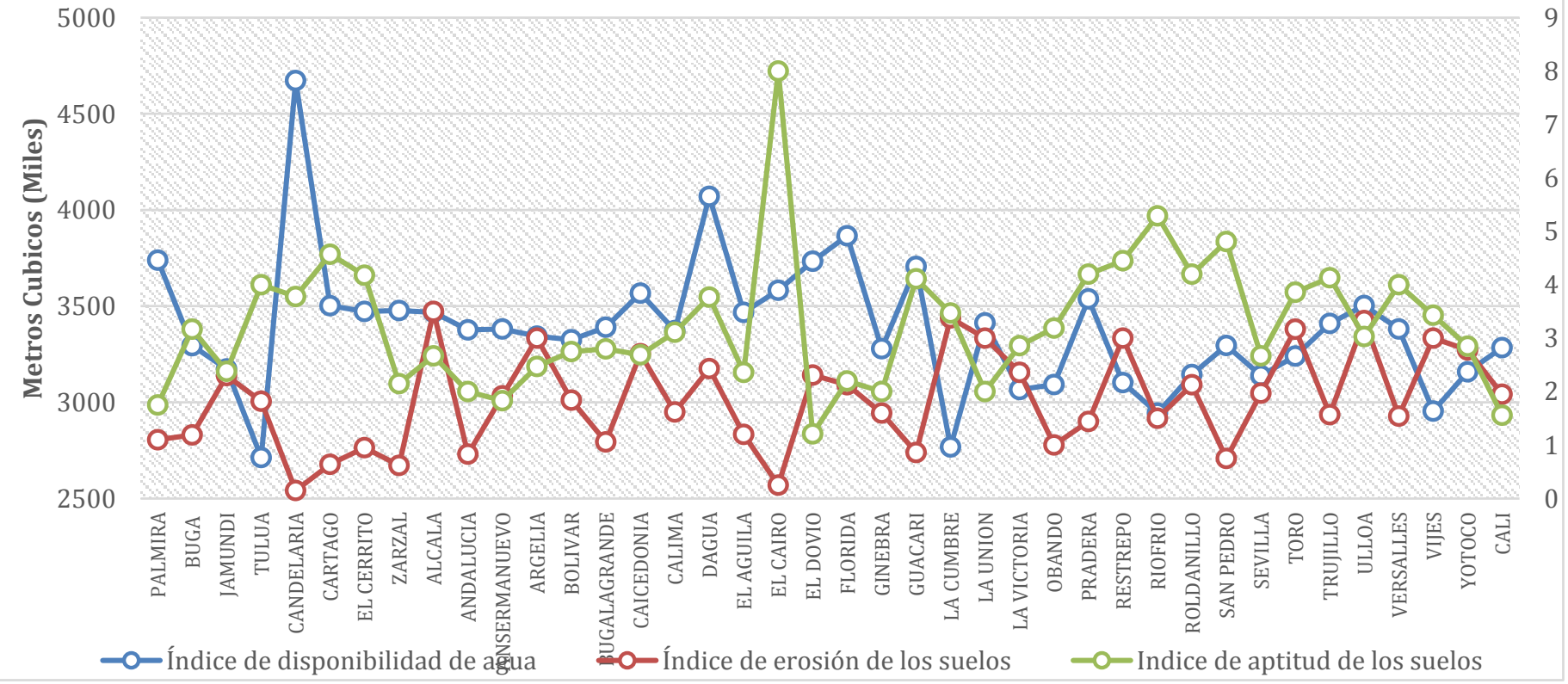

Figura 2. Disponibilidad de agua, erosión de suelos y aptitud por municipios del Valle del Cauca. Fuente: Cálculos Centre de Estudios sobre Desarrollo Económico (CEDE) con base de datos suministrados por el IGAC, 2005.

\footnotetext{
5 Dependencias de la administración municipal como: la secretaria de infraestructura, la secretaria de desarrollo social y la oficina asesora de planeación (MINESTERIO DE MEDIO AMBIENTE, 2004).
} 
Específicamente, los informes ambientales realizan un análisis enfocado a la inversión ambiental ${ }^{6}$ por municipio. Argumentando que la inversión y la ejecución presupuestal son una herramienta importante de la planeación, a través de las cuales se dirige la gestión en un periodo de gobierno; el cumplimiento en estas herramientas muestra un logro de las metas de los planes de acción ejecutados y las ejecuciones presupuestales en correspondencia con lo programado en el plan de desarrollo (Contraloría Departamental del Valle del Cauca 2010). Por lo cual, dentro de esta investigación se utiliza como variable proxy de la gestión ambiental municipal su nivel de inversión ambiental, dado que esta es la "materialización", el "resultado" de un proceso social y político continuo en el que intervienen diversos actores y en el que se definen, formulan y ejecutan un conjunto de acciones que tienen como finalidad el desarrollo sostenible de un territorio (González 2001).

Los resultados del informe ambiental evidencian las diferencias municipales existentes en el departamento con respecto al tema ambiental. Según el informe: "De la evaluación documental efectuada al componente ambiental de los instrumentos de planificación y presupuesto, rendidos por los 38 municipios, se determina que únicamente 6 municipios presentaron una articulación alta, denotando una mejora en los procesos de planificación de su gestión ambiental, en catorce municipios la coherencia fue parcial entre los contenidos ambientales, y 16 municipios mostraron una mínima articulación entre los instrumentos y por ende al cumplimiento del Plan de Desarrollo en la Vigencia" (Contraloría Departamental del Valle del Cauca 2010, p.191). El informe ambiental discute que existen deficientes mecanismos y estrategias de seguimiento y monitoreo a los Planes de Desarrollo, que le permita a los municipios, identificar desviaciones frente a los objetivos y metas propuestas, a fin de realizar los ajustes y acciones correctivas correspondientes.

Estos resultados son la base en el análisis de la gestión ambiental del Valle del Cauca, ya que como se puede observar en la Figura 3, existen también diferencias municipales en la inversión ambiental a nivel per-cápita. En el estudio de los 38 de los 42 municipios $^{7}$ del departamento sujetos al análisis de la controlaría municipal, se observa que municipios como Calima, El Águila, Versalles, Bolívar, Candelaria, y Zarzal presentan mayores niveles de inversión per-cápita; mientras municipios como Jamundí, Caicedonia, Pradera, Dagua, Toro, La Victoria y Guacarí muestran los niveles más bajos de inversión ambiental per-cápita. Lo cual indica que las diferencias municipales en temas ambientales no solo dependen del tamaño de la población ni del nivel de ingresos del municipio, ya que municipios de mayor categoría municipal como Jamundí y Buga presentan bajos valores en la inversión ambiental per-cápita, y municipios de menor categoría municipal como Calima, Bolívar, El Águila, Zarzal y Versalles presentan altos valores en su inversión ambiental per-cápita.

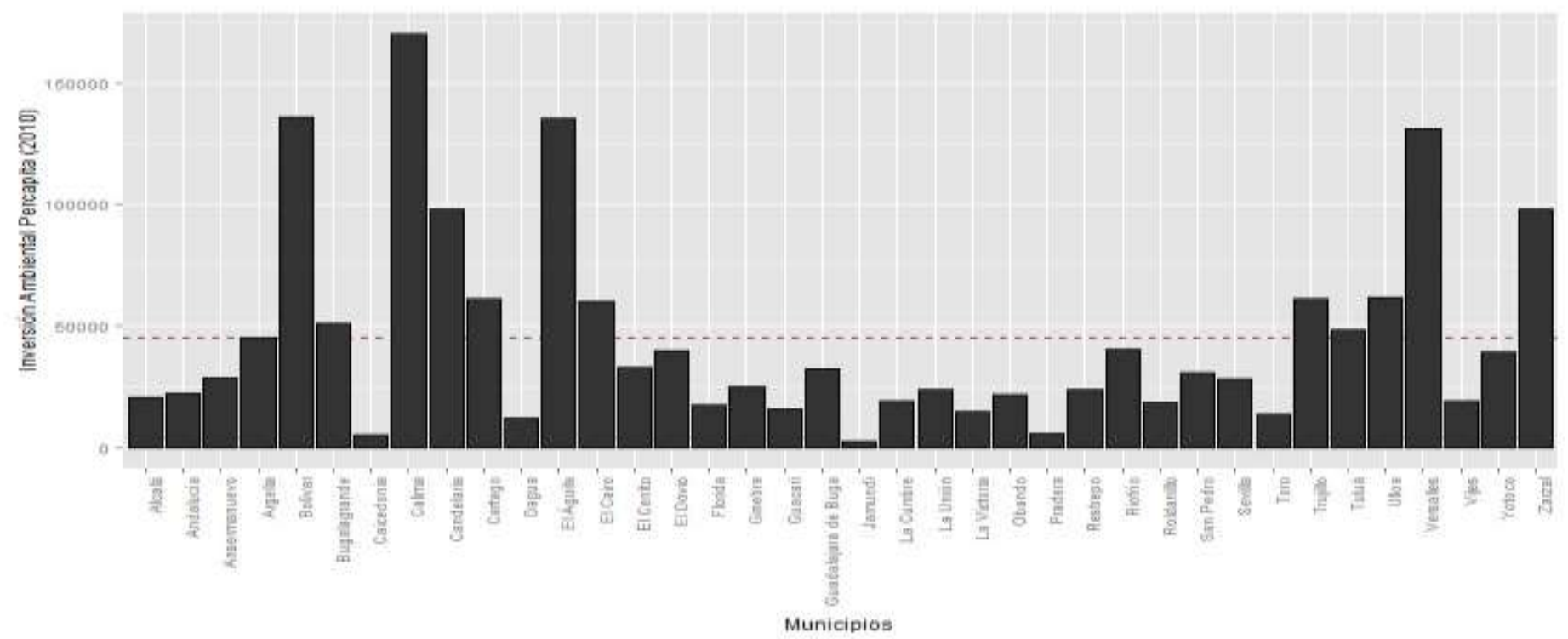

Figura 3. Inversión Ambiental Municipal Per-cápita 2010. Fuente: Elaboración Propia con base en la Contraloría Departamental del Valle del Cauca (2010).

\footnotetext{
${ }^{6}$ Esta inversión ambiental es analizada en cuatro componentes: prevención y atención de desastres, agua potable y saneamiento básico, medio ambiente y agropecuario.
}

${ }^{7}$ El análisis desarrollado por parte de la Contraloría Departamental del Valle del Cauca, excluye cuatro municipios: Cali, Buenaventura, Yumbo y Palmira. 
Ambiente y Sostenibilidad 2015 (5): 78-96

Revista del Doctorado Interinstitucional en Ciencias Ambientales

ISSN: 2339-3122

Digital

Un análisis con mayor profundidad sobre el comportamiento de la inversión municipal ambiental muestra que existen desigualdades municipales en términos de inversión ambiental municipal por categoría municipal, gasto total e inversión ambiental per-cápita. La Figura 4 muestra la relación de la inversión ambiental municipal versus el gasto total municipal, se observa que los municipios no muestran una relación directa entre inversión ambiental y gasto del municipio. Es decir, a un mayor nivel gasto municipal no hay un mayor nivel de inversión ambiental, o viceversa. Dichas desigualdades, son corroboradas al observar que existen diferentes niveles de inversión ambiental per-cápita ${ }^{8}$ por categoría municipal en todos los municipios de análisis.

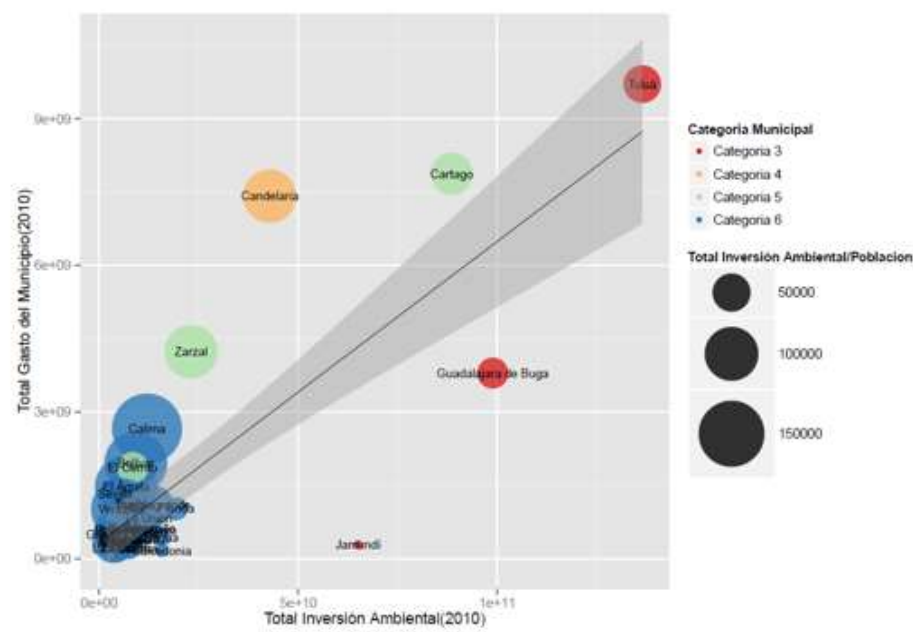

Figura 4. Inversión Ambiental Municipal vs Gasto Total Municipal. Fuente: Elaboración Propia con base en la Contraloría Departamental del Valle del Cauca (2010).

\section{METODOLOGÍA}

La pregunta de investigación es ¿por qué los municipios del Valle del Cauca responden de manera desigual en su gestión ambiental, en el año 2005'? La hipótesis es que las habilidades o atributos socioeconómicos y de gestión con lo que cuenten los diferentes actores del municipio inciden en cómo se responde a la Gestión del Medio Ambiente. La opción para abordar este análisis, se presenta en el concepto de gobernanza, dado que esté, puede ser adaptado para explicar la habilidad del municipio para resolver asuntos colectivos, en este caso la gestión ambiental. Como lo indica Wallace \& Wallace (2000), la gobernanza se ha transformado en una

\footnotetext{
${ }^{8}$ Total Inversión Ambiental municipal/ Población total municipal.

${ }^{9}$ El análisis se desarrolla para el 2005, debido a la restricción de datos para un mismo año de análisis.
}

actividad de múltiples niveles, intricadamente institucionalizada y especialmente diversa, al tiempo que la representación, la lealtad y la identidad siguen estando empecinadamente ancladas en las comunidades étnicas, regionales y nacionales.

Para responder a la pregunta se usa un enfoque metodológico de tipo descriptivo y analítico. Basado en el análisis desarrollado por Daniel Kaufman y Aart Kraay, quienes conformaron el programa que determina los indicadores de gobernanza para el Banco Mundial. Donde se definen seis dimensiones de gobernabilidad ${ }^{10}$ : Voz y Rendición de Cuentas, Estabilidad Política y Ausencia de Violencia, Efectividad Gubernamental, Calidad Regulatoria, Estado de Derecho y Control de la corrupción (Kaufmann 2001) (Figura $5)$.

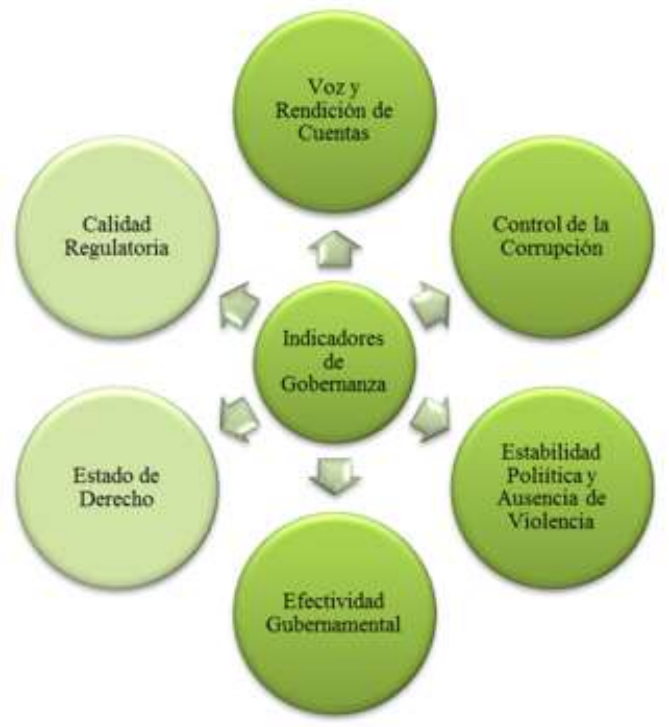

Figura 5. Indicadores de la Gobernanza por el Banco Mundial. Fuente: Kaufmann (2001).

El estudio se realiza en dos etapas, inicialmente con un análisis descriptivo para el año 2005, permitiendo alinear los datos y realizar inferencias entre las variables de gestión ambiental y gobernanza para el mayor número de los municipios del departamento y una segunda etapa con un análisis clúster para el mismo año, que permite observar como es el comportamiento de estas dimensiones de gobernanza de manera conjunta versus la gestión ambiental (Tabla 1). Finalmente, con base en las agrupaciones obtenidas del análisis clúster para el año 2005 se realiza un comparativo

10 Dada la limitación en los datos, por el año de análisis y por el mayor número de municipios solo se cuenta con variables que permiten considerar la gobernanza municipal a través de la dimensión de la efectividad del Gubernamental, Voz y Rendición de Cuentas, Estabilidad Política y Ausencia de Violencia y Control de la Corrupción. 
Tabla 1. Variables de Gobernanza y Gestión Ambiental utilizadas en la Investigación.

\begin{tabular}{|c|c|c|c|}
\hline Variable & Descripción & $\begin{array}{l}\text { Periodo } \\
\text { de } \\
\text { Tiempo }\end{array}$ & Fuente \\
\hline \multicolumn{4}{|l|}{ Gestión Ambiental } \\
\hline $\begin{array}{l}\text { Inversión Ambiental Municipal Per- } \\
\text { Cápita }\end{array}$ & $\begin{array}{l}\text { Es la cantidad de dinero destinada a temas ambientales como: Agua y } \\
\text { Saneamiento Básico, Atención y Prevención de Desastres, Medio } \\
\text { Ambiente y el sector Agropecuario. Esta variable está en precios } \\
\text { nominales y divididos sobre el número de personas del municipio. }\end{array}$ & $\begin{array}{c}2005 ; \\
2010\end{array}$ & $\begin{array}{l}\text { Contraloría } \\
\text { Departamental } \\
\text { del Valle del } \\
\text { Cauca. }\end{array}$ \\
\hline \multicolumn{4}{|l|}{ Voz y Rendición de cuentas } \\
\hline Rendición de Cuentas & $\begin{array}{l}\text { Frecuencia y modalidad en la que los municipios hacen rendición de } \\
\text { cuentas a la ciudadanía. }\end{array}$ & 2005 & SIGOT* $^{*}$ \\
\hline \multicolumn{4}{|l|}{$\begin{array}{c}\text { Estabilidad Política y Ausencia de } \\
\text { Violencia }\end{array}$} \\
\hline Acciones Armadas & $\begin{array}{l}\text { Número de acciones armadas de los grupos irregulares (FARC, ELN, } \\
\text { Autodefensas y Bandas emergentes) y los combates por iniciativa de la } \\
\text { Fuerza pública hacia los irregulares, que se presentan en el municipio. }\end{array}$ & 2005 & SIGOT. \\
\hline $\begin{array}{l}\text { Desplazamiento Forzado-Personas } \\
\text { Recibidas }\end{array}$ & $\begin{array}{l}\text { Número de personas recibidas por municipio, a causa del } \\
\text { desplazamiento por conflicto armado. }\end{array}$ & 2005 & SIGOT. \\
\hline \multicolumn{4}{|l|}{ Efectividad Gubernamental } \\
\hline Eficacia & $\begin{array}{l}\text { Representa el nivel de cumplimiento-físico del Plan de Desarrollo por } \\
\text { parte del municipio. El indicador se construye siguiendo la metodología } \\
\text { propuesta por el Departamento Nacional de Planeación }(\mathrm{DNP}) \text {, resulta } \\
\text { de ponderar los índices de eficacia de los sectores básicos y no básicos, } \\
\text { atribuyéndoles una participación del } 60 \% \text { y } 40 \% \text {, respectivamente. La } \\
\text { variable esta medida en porcentaje y sus rangos de niveles de } \\
\text { cumplimiento están así: sobresaliente }(>=80) \text {, Satisfactorio }(>=70 \text { y }<80) \text {, } \\
\text { Medio }(>=60 \text { y }<70) \text {, Bajo }(>=40 \text { y }<60) \text { y Critico }(<40) \text {. }\end{array}$ & 2005 & $\begin{array}{l}\text { Federación } \\
\text { Colombiana de } \\
\text { Municipios. }\end{array}$ \\
\hline Eficiencia & $\begin{array}{l}\text { Esta variable mide la relación entre productos obtenidos e insumos } \\
\text { utilizados por un municipio en el proceso de producción de bienes y de } \\
\text { prestación de servicios de educación, salud y agua potable. El indicador } \\
\text { se construye siguiendo la metodología determinada por el } \\
\text { Departamento Nacional de Planeación, la cual permite estimar la } \\
\text { eficiencia técnica relativa de los municipios en los sectores de mayor } \\
\text { inversión social a partir de la especificación de seis funciones de } \\
\text { producción. Esta metodología asigna } 100 \text { puntos a las entidades } \\
\text { (municipios) más eficientes y estima, a partir de allí, la eficiencia de las } \\
\text { demás en una escala que va de } 0 \text { a } 100 \text { puntos. }\end{array}$ & 2005 & $\begin{array}{l}\text { Federación } \\
\text { Colombiana de } \\
\text { Municipios. }\end{array}$ \\
\hline Requisitos Legales & $\begin{array}{l}\text { Esta variable evalúa el cumplimiento del marco normativo previsto por } \\
\text { la Ley } 715 \text { de } 2001 \text {, la Ley } 1176 \text { de } 2007 \text { y los decretos reglamentarios, } \\
\text { relacionados con la ejecución de los recursos del Sistema General de } \\
\text { Participaciones (SGP). La variable esta medida en porcentaje y sus } \\
\text { rangos de niveles de cumplimiento están así: sobresaliente }(>=80) \text {, } \\
\text { Satisfactorio }(>=70 \text { y }<80) \text {, Medio }(>=60 \text { y }<70) \text {, Bajo }(>=40 \text { y }<60) \text { y } \\
\text { Critico }(<40) \text {. }\end{array}$ & 2005 & $\begin{array}{l}\text { Federación } \\
\text { Colombiana de } \\
\text { Municipios. }\end{array}$ \\
\hline \multicolumn{4}{|l|}{ Control de la Corrupción } \\
\hline Índice de Transparencia Municipal & $\begin{array}{l}\text { El Índice de Transparencia Municipal, ITM, indaga sobre el } \\
\text { cumplimiento de normas y estándares de gestión, la visibilidad que da } \\
\text { a sus actos las autoridades y los procesos de promoción de la } \\
\text { participación que adelantan, con el fin de establecer el nivel de riesgo de } \\
\text { corrupción que configuren estas prácticas. La calificación definitiva de } \\
\text { cada municipio se obtiene ponderando la calificación de los tres } \\
\text { componentes que la componen así: cumplimiento de normas y } \\
\text { estándares ( } 40 \%) \text {, visibilidad ( } 40 \%) \text { y promoción de la participación } \\
\text { ciudadana (20\%). Los resultados se agrupan en cuatro niveles de riesgo: } \\
\text { muy alto, alto, medio, moderado y bajo. }\end{array}$ & 2005 & $\begin{array}{l}\text { Corporación } \\
\text { Transparencia } \\
\text { por Colombia. }\end{array}$ \\
\hline
\end{tabular}

*Sistema de Información Geográfica para la Planeación y el Ordenamiento Territorial. 
ISSN: 2339-3122

Digital

\section{RESULTADOS Y DISCUSIÓN}

\section{Indicadores de gobernanza vs inversión ambiental per-cápita}

\section{Voz y Rendición de Cuentas}

Esta dimensión de análisis mide en qué grado los ciudadanos de un país cuentan con libertades civiles y los derechos políticos para participar en la selección de sus gobernantes. Refleja así mismo cuán preparado está el Gobierno para rendir cuentas y ser auditado tanto por los ciudadanos como por las distintas instituciones democráticas y medios de comunicación.

El análisis Clúster es una técnica estadística de agrupamiento por conglomerado de acuerdo a distintas variables, con lo que se busca identificar características de los municipios con diferencias en su gestión ambiental. Para este estudio se utilizaron variables como inversión ambiental municipal, rendición de cuentas, eficiencia municipal, índice de requisitos legales, gestión municipal, número de personas desplazadas por municipio, hectáreas de coca y número de acciones armadas (Tabla 1).

Con esta metodología se busca formar grupos a partir de este conjunto de variables de tal forma que estos grupos estén formados por elementos los más parecidos posible (homogéneos) y a su vez lo más diferentes (heterogéneos) entre los grupos (Hair et al. 1998). Basado en el tipo de datos obtenidos en el análisis, se utiliza un clúster tipo jerárquico. Este tipo es el más apropiado cuando se tienen pocos datos y se requiere encontrar fácilmente soluciones con un número creciente de grupos.

Para la realización del clúster jerárquico se calcula una medida estadística que cuantifica que tan similar o diferentes son dos casos ante la selección de un grupo que forman, y con esto se calcula finalmente el número de grupos necesarios para la representación de todos los datos. Sin embargo, dado que tenemos datos de tipo continuo y categórico, una diferente medida es utilizada para formar grupos similares. Dado que ninguna medida de distancia en este tipo de clúster es ajustable para ambos tipos de variables (Norusis 2011). Por esta razón, el análisis factorial para datos mixtos es utilizado para agrupar todas las variables en un índice. Después de la elaboración del análisis factorial, se utiliza la agrupación jerárquica aglomerativa con los resultados del análisis factorial.
La voz y rendición de cuentas permite analizar si el control social por parte del ciudadano ejercido en la rendición de cuentas refleja mejores resultados en la gestión ambiental municipal. Por medio de la variable modalidad de rendición de cuentas para el año 2005 se encontró que en los municipios del Valle, la dimensión de gobernanza voz y rendición de cuentas no tiene un efecto directo sobre la gestión ambiental de los municipios. Dado que, como se observa en la Figura 6 los municipios con modalidad anual en su rendición de cuentas presentan mayores valores en su inversión ambiental per-cápita en comparación con las otras modalidades.

La relación observada entre la inversión ambiental per-cápita y modalidad en la rendición de cuentas cuestiona la calidad de estas rendiciones en las instancias gubernamentales municipales, así mismo como la eficiencia en la modalidad de las rendiciones de cuentas. Debido a que los municipios con modalidad mensual, cuatro veces por año y tres veces por año en su rendición de cuentas, no presentan grandes niveles de inversión ambiental per-cápita, de los doce municipios que se encuentran bajo estas modalidades de rendición de cuentas solo cuatro están por encima del valor promedio municipal en inversión ambiental per-cápita (Obando, Riofrio, Ansermanuevo y Florida). Mientras que los municipios con modalidad anual presentan los mayores valores en inversión ambiental per-cápita, de los 14 municipios bajo esta modalidad la mitad presentan valores por encima del valor promedio en la inversión ambiental municipal (Figura 6).

Los resultados obtenidos corroboran la definición de la rendición de cuentas dada por Andreas Villalpando (2009). El autor la entiende como: el proceso donde "A" rinde cuentas a "B" cuando está obligado a informarle sobre sus acciones y decisiones, a justificarlas y a sufrir el castigo correspondiente en caso de mala conducta (Villalpando 2009). Argumenta que los pilares de la rendición de cuenta son la información, la justificación y la sanción. Sin embargo, reconoce que las tres no forman un núcleo de "atributos necesarios" que de manera 
binaria estén o presentes o ausentes y que deban estar presentes en todas las instancias de rendición de cuentas.

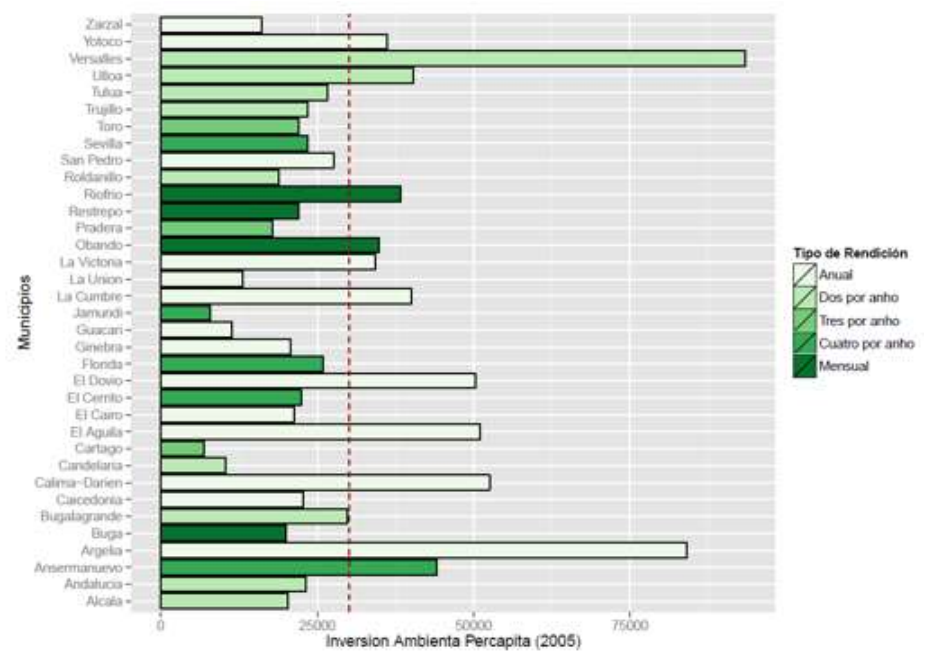

Figura6. Inversión Ambiental Municipal Per-Cápita por Modalidad y Frecuencia de Rendición de Cuentas en los Municipios del Valle del Cauca. Fuente: Elaboración propiacon base en Contraloría Departamental del Valle del Cauca-SIGOT.

Figura 6. Inversión Ambiental Municipal Per-Cápita por Modalidad y Frecuencia de Rendición de Cuentas en los Municipios del Valle del Cauca. Fuente: Elaboración propia con base en la Contraloría Departamental del Valle del Cauca-SIGOT.

\section{Estabilidad Política y Ausencia de Violencia}

La Estabilidad Política y Ausencia de Violencia mide las percepciones de la población respecto de si el gobierno puede ser desestabilizado o derrocado por medios inconstitucionales, incluida la violencia y el terrorismo. Esta dimensión comprende mediciones sobre la amenaza del terrorismo y los costos que implica, estabilidad del gobierno, conflictos armados, demostraciones violentas, frecuencias de asesinatos políticos, desapariciones, variables que expresan sobre todo la capacidad del régimen político de sobrevivir a situaciones de riesgo.

Desde esta perspectiva de Estabilidad Política y Ausencia de Violencia, el análisis se realizó por medio de variables como acciones armadas y desplazamiento forzado en el municipio. Se tiene que la violencia e inestabilidad surgen como consecuencia del rápido cambio social y de la veloz movilización política de nuevos grupos, junto con el lento desarrollo de las instituciones políticas. Estos cambios desmejoran los fundamentos de la autoridad y complican la creación de nuevas bases de asociación e instituciones políticas que unan la legitimidad a la eficacia (Montaño 2009).

El Anexo 1 y 2 muestra la relación de las acciones armadas y el desplazamiento forzado con la inversión ambiental percápita, donde se observa que en un gran número de los municipios analizados, la presencia de acciones armadas y desplazamiento tiene relación inversa con su inversión ambiental per-cápita. Lo cual muestra que desde esta perspectiva de gobernanza, la ausencia de violencia si tiene efectos positivos sobre la gestión ambiental municipal.

Los conflictos sociopolíticos tienen un efecto negativo sobre el desarrollo integral del Departamento. La expresión de estos conflictos se materializa en acciones violentas provenientes de los diferentes grupos armados de forma ilegal: paramilitares, guerrillas y delincuencia común (CVC 2002). El Anexo 1 muestra la relación entre la inversión ambiental per cápita y las acciones armadas para 18 municipios del Valle, donde de los 8 municipios que presentan acciones armadas por encima del promedio municipal solo el Calima Darién presenta un valor alto en su inversión ambiental per-cápita, mientras que los municipios con un número de acciones armadas por debajo del promedio municipal como: Ansermanuevo, el Aguila, la Cumbre, el Dovio, Ulloa y Versalles, presentan valores en su inversión ambiental per-cápita por encima del promedio municipal, mostrando que el efecto de las acciones armadas en la inversión ambiental municipal per-cápita es en un mayor número de municipios negativo.

De esta manera, se realiza el análisis en la variable de desplazamiento forzoso, ya que esté desencadena varios conflictos ambientales y de gobernanza, generados por la presencia de asentamientos humanos en zonas de riesgo, por la mayor demanda de servicios sociales básicos, entre muchos otros factores (CVC 2002). El Anexo 2 presenta la relación entre la inversión ambiental municipal per-cápita y el número de personas recibidas en el municipio por desplazamiento forzado para los municipios del Valle. Se utiliza el número de personas recibidas pues como lo expresa la CVC uno de los impactos relacionados con el desplazamiento se presenta en: "el desmejoramiento de los procesos de gobernabilidad en las cabeceras municipales receptoras de población desplazada, ante las diferentes demanda sociales de los nuevos habitantes" (CVC 2002). Se observa que en los municipios donde el número de personas recibidas es menor que el promedio municipal, trece municipios sobrepasan el promedio municipal en inversión ambiental per cápita. Mientras que de los municipios (Cartago y Tuluá) que presentan unos valores de personas recibidas por desplazamiento forzado por encima del valor promedio municipal, presentan una inversión ambiental municipal por debajo del promedio municipal. Revelando entonces que, en conjunto donde hay mejores indicativos de elección colectiva hay mejor gestión ambiental (Anexo 2). 
Ambiente y Sostenibilidad 2015 (5): 78-96

Revista del Doctorado Interinstitucional en Ciencias Ambientales

ISSN: 2339-3122

Digital

\section{Efectividad Gubernamental}

La dimensión de Efectividad Gubernamental mide la calidad de los servicios públicos, la calidad del servicio civil y el grado de su independencia de las presiones políticas, la calidad de la formulación e implementación de las políticas y la credibilidad de los compromisos gubernamentales ante tales políticas. Para el análisis de esta dimensión de gobernanza, se utilizó la metodología de medición y análisis del desempeño municipal diseñada por el Departamento Nacional de Planeación (DNP).

El Anexo 3 presenta la Inversión Ambiental Municipal versus el Índice de Eficacia municipal, donde se observa que el efecto de esta dimensión de gobernanza sobre la gestión ambiental no tiene una fuerte incidencia. Pues de los 14 municipios con un índice de eficacia en su gestión municipal por debajo del valor promedio municipal, 8 municipios presentan valores por debajo del promedio municipal en su Inversión Ambiental Municipal Per-cápita, mostrando un efecto directo entre eficacia y gestión ambiental. No obstante, los municipios que presentan índices de eficacia por encima del promedio municipal (21 municipios), solo 9 municipios presentan una inversión ambiental municipal per-cápita por encima del promedio municipal. El análisis de este componente manifiesta que en los municipios del Valle del Cauca existe una debilidad en materia del cumplimiento de metas establecidas en el tema ambiental.

El Anexo 4 presenta la Inversión Ambiental Municipal PerCápita versus Índice de Eficiencia, se observa que la incidencia en la inversión ambiental per-cápita es débil. 20 municipios que presentan un índice de eficiencia por debajo del promedio municipal de 53 puntos, solo 13 municipios presentan una inversión ambiental per-cápita por debajo del promedio; dejando entre ver que la relación entre este componente y la gestión ambiental es más del $50 \%$, cuando se utiliza para explicar los casos en donde se presenta menor gestión ambiental. No obstante, se muestra que en los 15 municipios que presentan un índice de eficiencia por encima del promedio municipal, únicamente 6 de ellos registran una inversión ambiental per-cápita por encima del promedio municipal. El estudio de este componente muestra que los municipios del Valle del Cauca no están optimizando la dotación de recursos humanos, financieros y físicos para producir diferentes bienes y servicios para la sociedad, por lo cual también se presentan desigualdades en su gestión ambiental.

El componente de requisitos legales versus la inversión ambiental municipal per-cápita se ve representado en el Anexo 5, exponiendo una clara incidencia entre los bajos valores del índice de requisitos legales y los bajos valores en inversión ambiental per-cápita. Se observa que 8 de los 11 municipios que tienen un índice de requisitos legales inferior al promedio municipal, manifiestan una inversión ambiental per-cápita por debajo al promedio municipal, lo cual manifiesta un efecto negativo entre el cumplimiento a los requisitos y condiciones establecidas por las normas legales para la gestión local en los sectores básicos y la inversión ambiental. Por otra parte, de los 24 municipios que poseen valores en el componente de requisitos legales por encima del promedio municipal solo 10 manifiestan una inversión ambiental per-cápita por encima del promedio municipal, mostrando que el efecto positivo del componente sobre la inversión ambiental no es grande.

Por último, el análisis del componente de Inversión Ambiental Municipal Per-Cápita versus Gestión Municipal permite observar que los municipios con menor capacidad administrativa y financiera son los que presentan en gran proporción los menores valores en la inversión ambiental per-cápita. El Anexo 6 permite apreciar que 21 municipios presentan un índice de gestión municipal menor al promedio municipal, donde 14 de ellos tienen una inversión ambiental per-cápita por debajo del promedio municipal. Del mismo modo, vale la pena resaltar que de los 14 municipios con índice de gestión municipal por encima del promedio municipal, 6 municipios presentan una inversión ambiental per-cápita superior al promedio municipal. En conclusión, el análisis de la relación entre la dimensión de Efectividad gubernamental y la inversión ambiental municipal per-cápita expone la importancia del buen uso de los recursos a disposición por parte del municipio para lograr mejores resultados en su gestión ambiental. Como se presentó anteriormente, los municipios con valores por debajo del valor promedio municipal en cualquiera de estos componentes (eficacia, eficiencia, gestión municipal) presentaban una inversión ambiental municipal per-cápita inferior al valor promedio municipal en la inversión ambiental per-cápita.

\section{Control de la Corrupción}

Por último, el análisis de la gobernanza y la gestión ambiental se enfoca en la dimensión del control de la corrupción. Entendiendo esta dimensión, como la que mide el punto en el cual el poder público es ejercido para beneficio privado, incluidas tanto pequeñas como grandes formas de corrupción, y la captura del Estado por las elites y los intereses privados. Es un apoyo a la rendición de cuentas, la transparencia literalmente significa que las ciudadanas y los ciudadanos deberían poder 'ver a través' del funcionamiento de las instituciones de gobernanza, lo cual implica que la información ha de estar a su disposición de manera gratuita y no se les debe impedir que busquen o compartan información. 


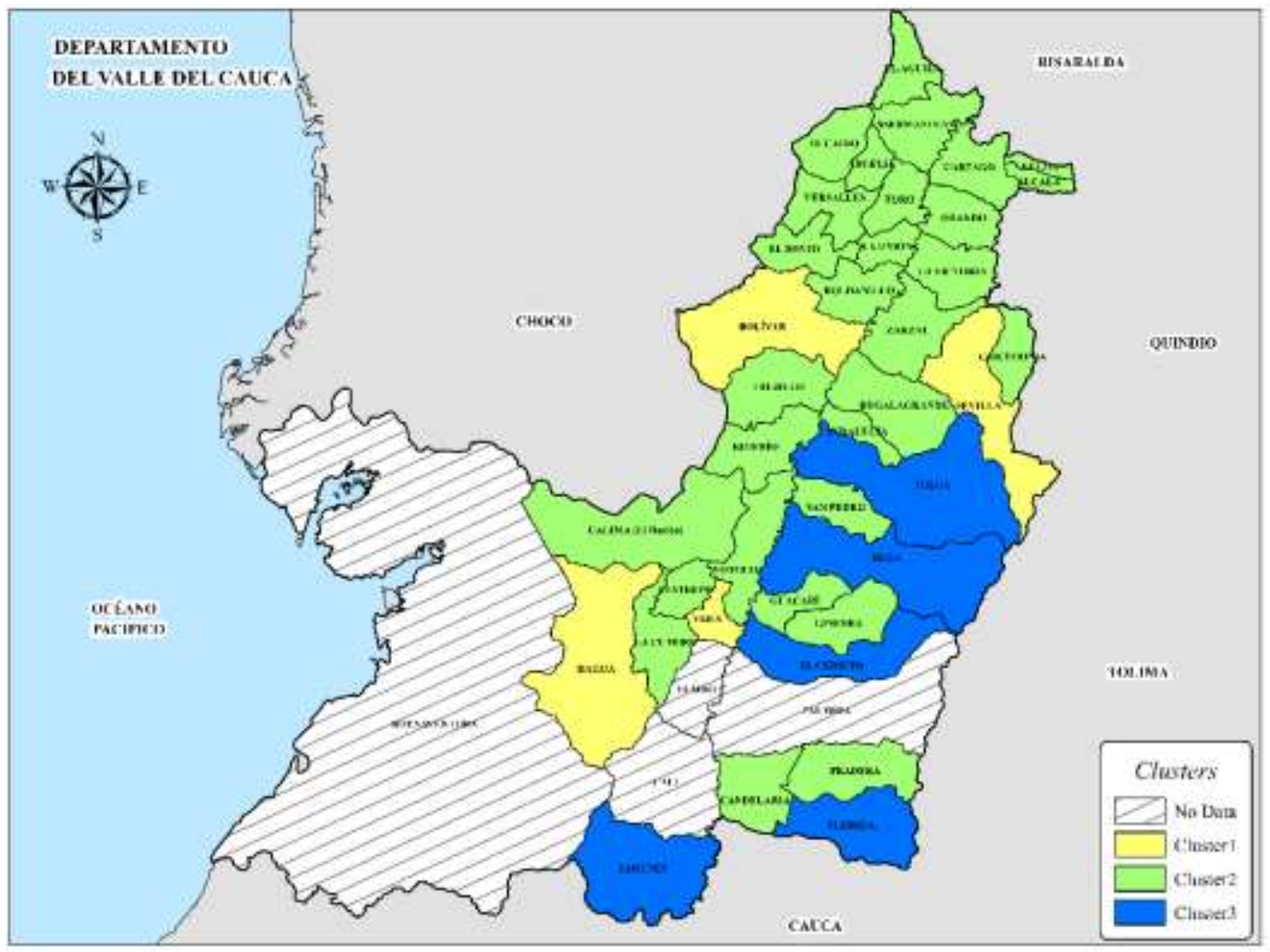

Figura 7. Resultados del análisis del Clúster Jerárquico. Fuente: Elaboración propia.

El análisis de esta dimensión de la gobernanza y su relación con la inversión ambiental municipal per-cápita, se llevará a cabo por medio del Índice de Transparencia Municipal (ITM). En el Anexo 7 se puede observar su relación con la inversión ambiental per-cápita ${ }^{1}$, con base en el Índice de Transparencia Municipal muestra que existe una relación positiva entre ambas. Además, tiene el hecho que las desigualdades en la inversión ambiental municipal per-cápita para los municipios del Valle del Cauca analizados se entienden en una gran proporción al ITM, debido que el índice de transparencia muestra un efecto proporcional sobre la inversión ambiental municipal per-cápita en 8 de los 10 municipios. De los municipios que muestran un ITM por encima del valor promedio municipal, solo Pradera y Jamundí presentan niveles de inversión ambiental per-cápita menores al valor promedio municipal, y en los municipios con índices de transparencia situados en niveles riesgo de corrupción alto y muy alto todos presentan una inversión ambiental municipal per-cápita por debajo del nivel promedio municipal.

\footnotetext{
${ }^{1}$ El análisis de esta dimensión se realiza solo para 10 municipios del Valle debido a la restricción de datos, basado en el análisis de la Corporación Transparencia por Colombia (2007).
}

\section{Gobernanza vs gestión ambiental}

En general, las dimensiones de gobernanza analizadas muestran una relación con la inversión ambiental per-cápita municipal como proxy de su gestión ambiental. Sin embargo, hasta el momento se ha observado cada dimensión de manera individual, lo cual no permite tener claridad sobre si la gobernanza como contexto social y económico de cada municipio incide en su habilidad para responder a la gestión ambiental. Por tal razón, se utiliza la técnica estadística del clúster jerárquico. La cual permite realizar un agrupamiento por conglomerado de acuerdo a distintas variables ${ }^{2}$.

Se observa que tres diferentes clúster fueron definidos a través del clúster jerárquico (Figura 7). El clúster 1 presenta el menor número de municipios (11\%) y un mayor promedio en el índice de requisitos legales, mientras el clúster 2 presenta el mayor número de municipios (76\%) y la mayor inversión ambiental per-cápita promedio y el clúster 3 tiene el 13\% del total de los municipios y muestra los mayores números

\footnotetext{
2 Para este caso, se utiliza las siguientes variables: inversión ambiental percápita municipal, frecuencia de rendición de cuentas, índice de eficacia de la gestión municipal, índice de requisitos legales , índice de gestión municipal, número de desplazados recibidos y número de acciones armadas en el municipio.
} 
Ambiente y Sostenibilidad 2015 (5): 78-96

Revista del Doctorado Interinstitucional en Ciencias Ambientales

ISSN: 2339-3122

Digital

promedio de acciones armadas y desplazados recibidos, con un 355 y 8 respectivamente. En otras palabras, el clúster 2 es el que tiene una mayor gestión ambiental en términos de inversión ambiental per-cápita con un menor número promedio de personas desplazadas recibidas total. Mientras el clúster 3 presenta el menor promedio de inversión ambiental per-cápita con el mayor número promedio de acciones armadas y personas desplazadas recibidas en total. Con base en esto se puede concluir que el contexto de gobernanza en el municipio si afecta su habilidad para responder a la gestión ambiental, y dentro de estos la dimensión de gobernanza que índice de una manera más directa es la estabilidad política y ausencia de violencia.

Por último, se realiza un análisis comparativo de la inversión ambiental per-cápita municipal en los municipios del Valle del Cauca entre el año 2005 y el 2010. Los resultados muestran que para el 2005 la mayoría de los municipios pertenecen al clúster 2 y este clúster tiene todos los municipios con una inversión ambiental per-cápita por encima del promedio municipal, a excepción del municipio de Bolívar que pertenece al clúster 1 . Por otro lado, para 5 años después se observa principalmente dos cosas: (1) en general, la inversión ambiental per-cápita disminuye drásticamente para todos los municipios del Valle del Cauca. (2) el comportamiento de los clúster se mantiene en términos de su inversión ambiental, el clúster 2 sigue manteniendo el mayor promedio de inversión ambiental per cápita mientras el clúster 3 en promedio presenta la menor. En conclusión, dentro de todos los factores socioeconómicos que existen en los municipios del Valle del cauca la gobernanza es un factor que permite explicar las desigualdades en la gestión ambiental del Departamento.

\section{CONCLUSIONES}

La investigación manifiesta el papel del municipio en la Gestión Ambiental, como actor fundamental dentro del Estado. Puesto que la gestión ambiental, se concibe como la organización de las actuaciones públicas y privadas, dirigidas a mantener el adecuado funcionamiento de los ecosistemas, generando un desarrollo que permita el mejoramiento de la calidad de vida de las poblaciones, bajo un enfoque global y es en el nivel local (el municipio), donde se manifiesta claramente la oferta y las restricciones de uso de los recursos naturales. Se muestra que en los factores, elementos y/o habilidades de cada municipio radica los buenos o malos resultados de la Gestión Ambiental. Los resultados obtenidos en la investigación muestran que en los municipios del Valle del Cauca, la gestión ambiental se presenta de forma desigual, existen diferencias en temas como: organización, planeación, herramientas técnicas, jurídicas y económicas con las que dispone cada ente territorial.

El análisis también muestra que en los municipios del Valle del Cauca, las habilidades municipales de gobernanza definidas por el Banco Mundial inciden las desigualdades existentes en cómo los municipios responden a su gestión ambiental. De las cuatro dimensiones analizadas se encontró que dimensiones como estabilidad política y ausencia de violencia, efectividad gubernamental y control de la corrupción permiten explicar que características o habilidades inciden una mayor o menor respuesta a la Gestión Ambiental. Por lo cual es válido decir que el mejorar la sociedad en herramientas de participación, de veedurías públicas, y de control de la corrupción podría llevar a un mejor "bienestar" en términos de gestión y desarrollo social. Sin embargo la realidad demuestra que esto no es así de sencillo, dado que coexisten otros elementos, otras características de la sociedad que determinan la forma de aprendizaje en su gestión ambiental y el contexto donde la emplean. Estos elementos de la sociedad, son la "plataforma", las bases de una buena gestión ambiental, lo importante no solo radica en las bases, está en cómo las construyen.

\section{REFERENCIAS}

COLOMBIA, 1994. Congreso de la República, LEY 136 DE 1994. Por la cual se dictan normas tendientes a modernizar la organización y el funcionamiento de los municipios. Diario Oficial No. 41.377 de 2 de junio de 1994.

CONTRALORIA DEPARTAMENTAL VALLE DEL CAUCA, CDVC.2010. Informe Anual sobre el Estado de los Recursos Naturales y el Medio Ambiente del Departamento del Valle del Cauca Vigencia 2010. Santiago de Cali.

CORPORACIÓN AUTÓNOMA REGIONAL DEL VALLE DEL CAUCA - CVC.2002. Plan de Gestión Ambiental Regional 2002-2012. Santiago de Cali.

CORPORACIÓN TRANSPARENCIA POR COLOMBIA. 2007. Colección Documentos Observatorio de Integridad No.9 Índice de Transparencia Municipal - Resultados 2005 y 2006 ISSN 1692 -1887. Bogotá, Colombia - Mayo de 2007.

MONTAÑO, A. D. 2009. La gestión de la violencia legítima: México y Chile en perspectiva comparada. Espacios Públicos, 12(25), 8-22.

GOBERNACION DEL VALLE DEL CAUCA.2005. Anuario Estadístico del Valle del Cauca 2005.

GONZÁLEZ, E. (2001). Gestión Ambiental en pequeños 
municipios. Revista Foro, 4, 42-57.

HAIR JR, J. F., ANDERSON, R. E., TATHAM, R. L., \& BLACK, W. C. (1998). Mukivariate Data Analysis, 5th edn (PrenticeHall, Upper Saddle River, NJ).

KAUFMANN, DANIEL; KRAAY, AART.2001. "Gobernabilidad y crecimiento en el largo plazo. Evidencia para Latinoamérica y el mundo". URL disponible en: www.worldbank.org/wbi/governance/pdf/growthgove.pdf.

MINISTERIO DEL MEDIO AMBIENTE. 2002. Sistema de Gestión Ambiental Municipal- Guía de Gestión Administrativa para la aplicación del SIGAM. Bogotá.

MINISTERIO DE MEDIO AMBIENTE.2004. Sistema de Gestión Ambiental Municipal-Guía para la formulación de la agenda ambiental municipal Bogotá.

NORUSIS, M.J.2011. "Clúster Analysis." Chapter 18 in IBM. SPSS. Statistics 19 Statistical Procedures Companion. Rancho Cordova, CA, USA: Pearson Education, Inc. ISBN-13:978-0321-74842-3.

VILLALPANDO, E. A. T. (2009). La rendición de cuentas (accountability) y la retórica de la nueva gestión pública. Espacios Públicos, 12(24), 71-89.

WALLACE, H; WALLACE, W.2000. Policy-Making in the European Union. Oxford University Press. 


\section{ANEXOS}

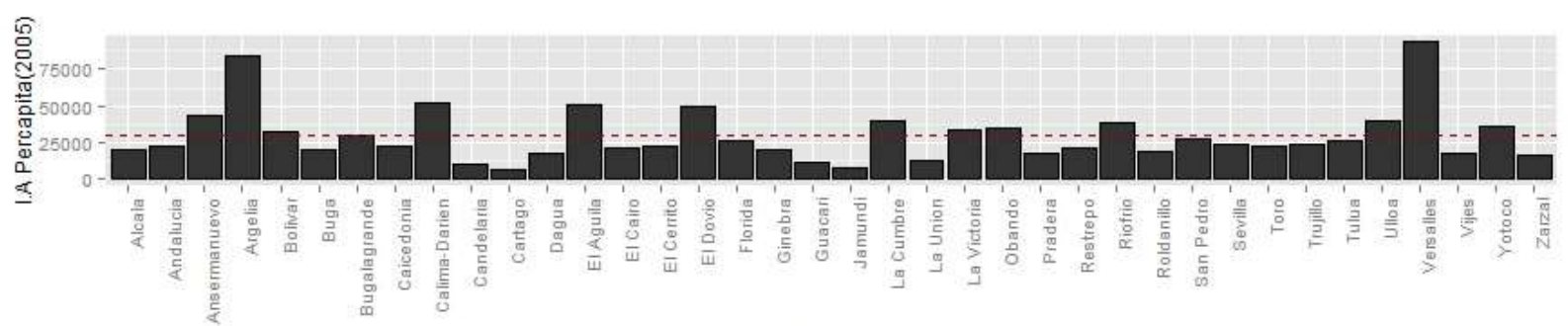

Municipios
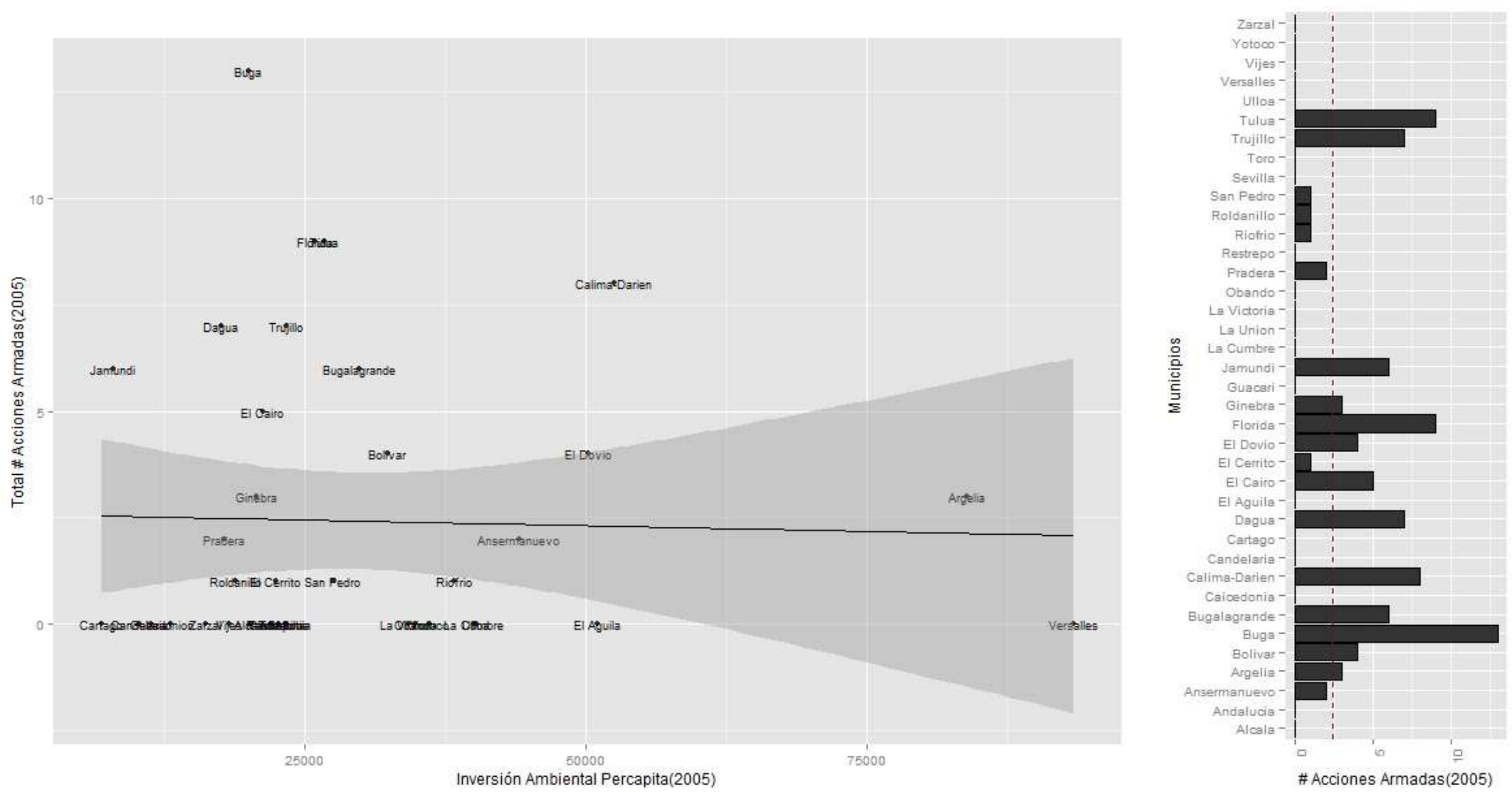

Anexo 1. Inversión Ambiental Municipal Per- Cápita vs Acciones Armadas en los Municipios del Valle del Cauca. Fuente: Elaboración propia con base en la Contraloría Departamental del Valle del Cauca-SIGOT. 


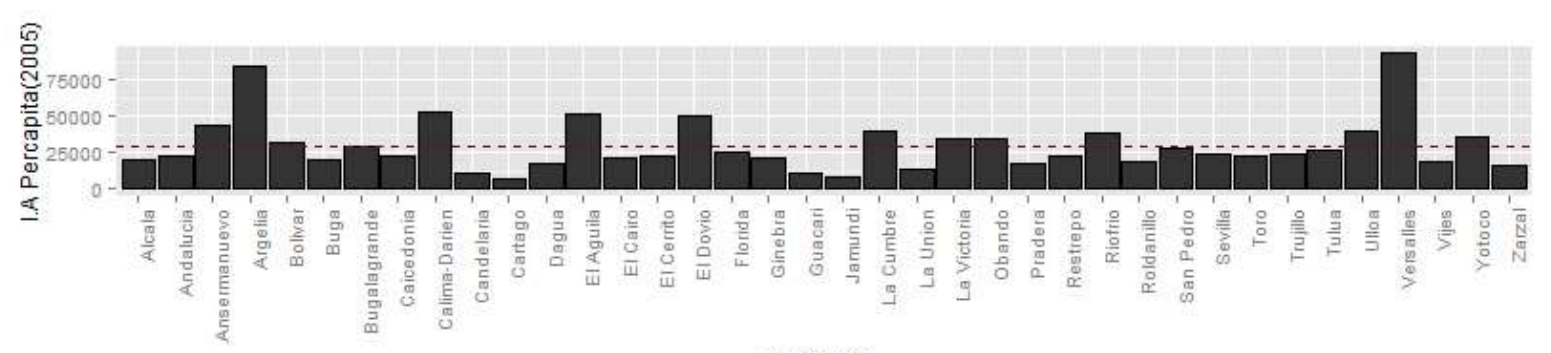

Municipios
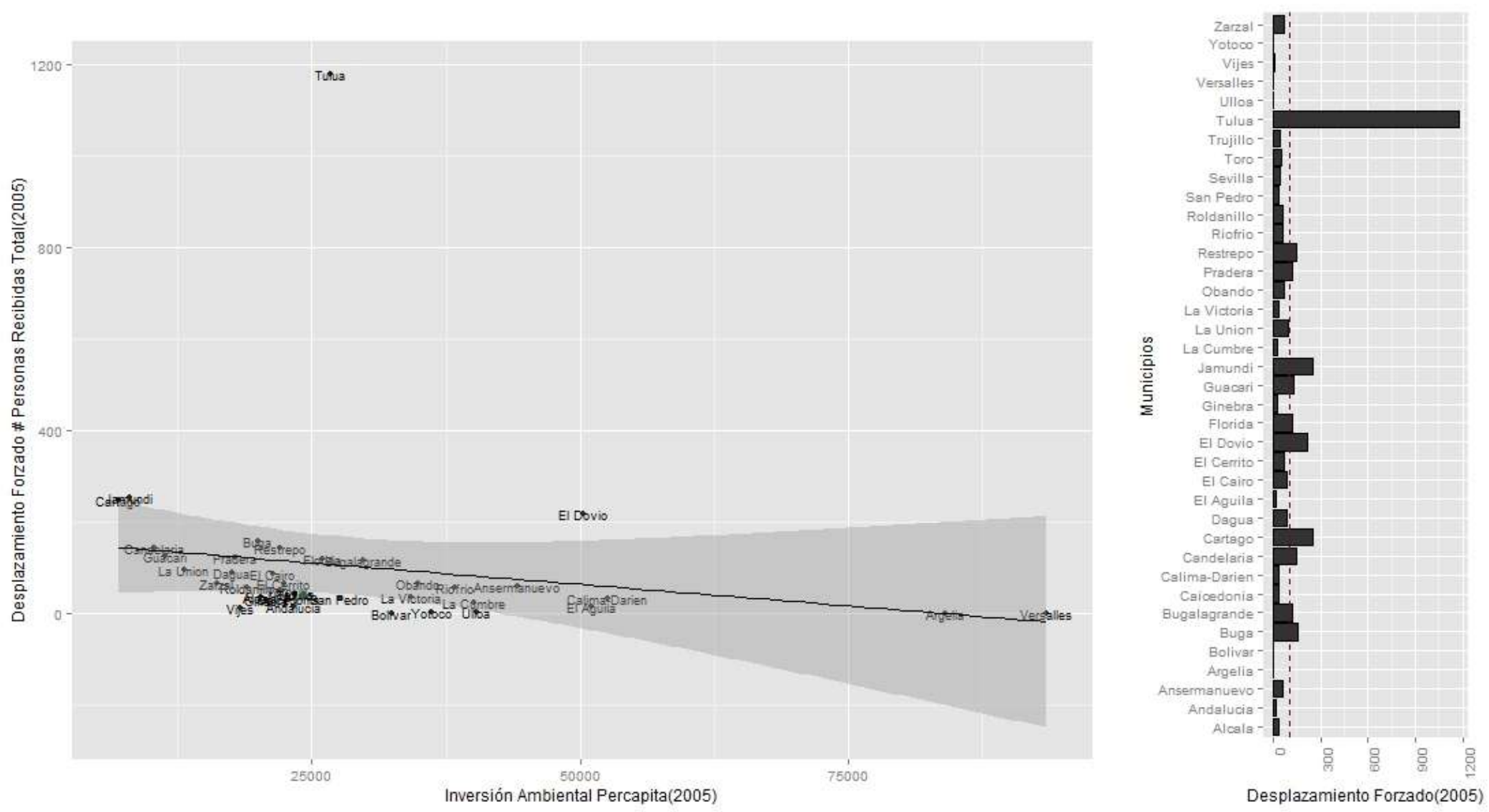

Anexo 2. Inversión Ambiental Municipal Per-Cápita vs Desplazamiento Forzado en los Municipios del Valle del Cauca. Fuente: Elaboración propia con base en la Contraloría Departamental del Valle del Cauca-SIGOT. 


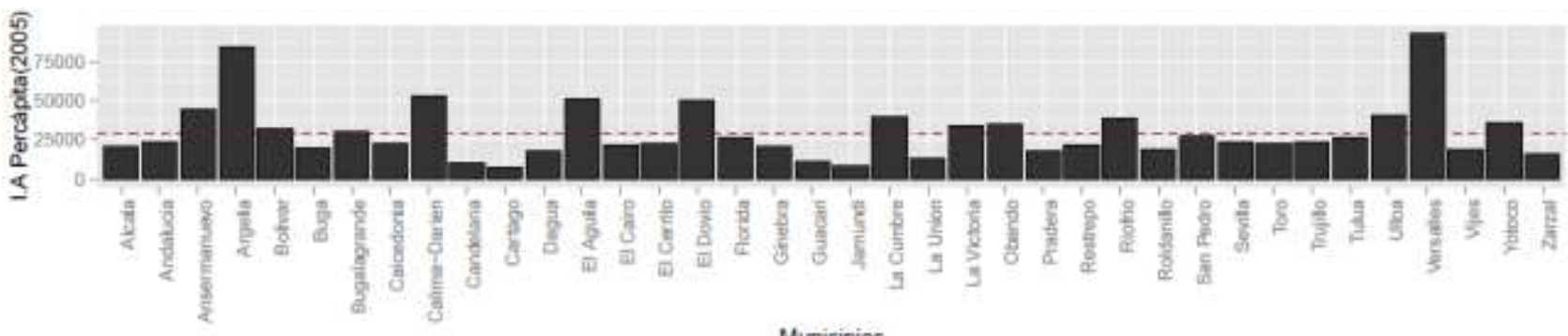

Municipios
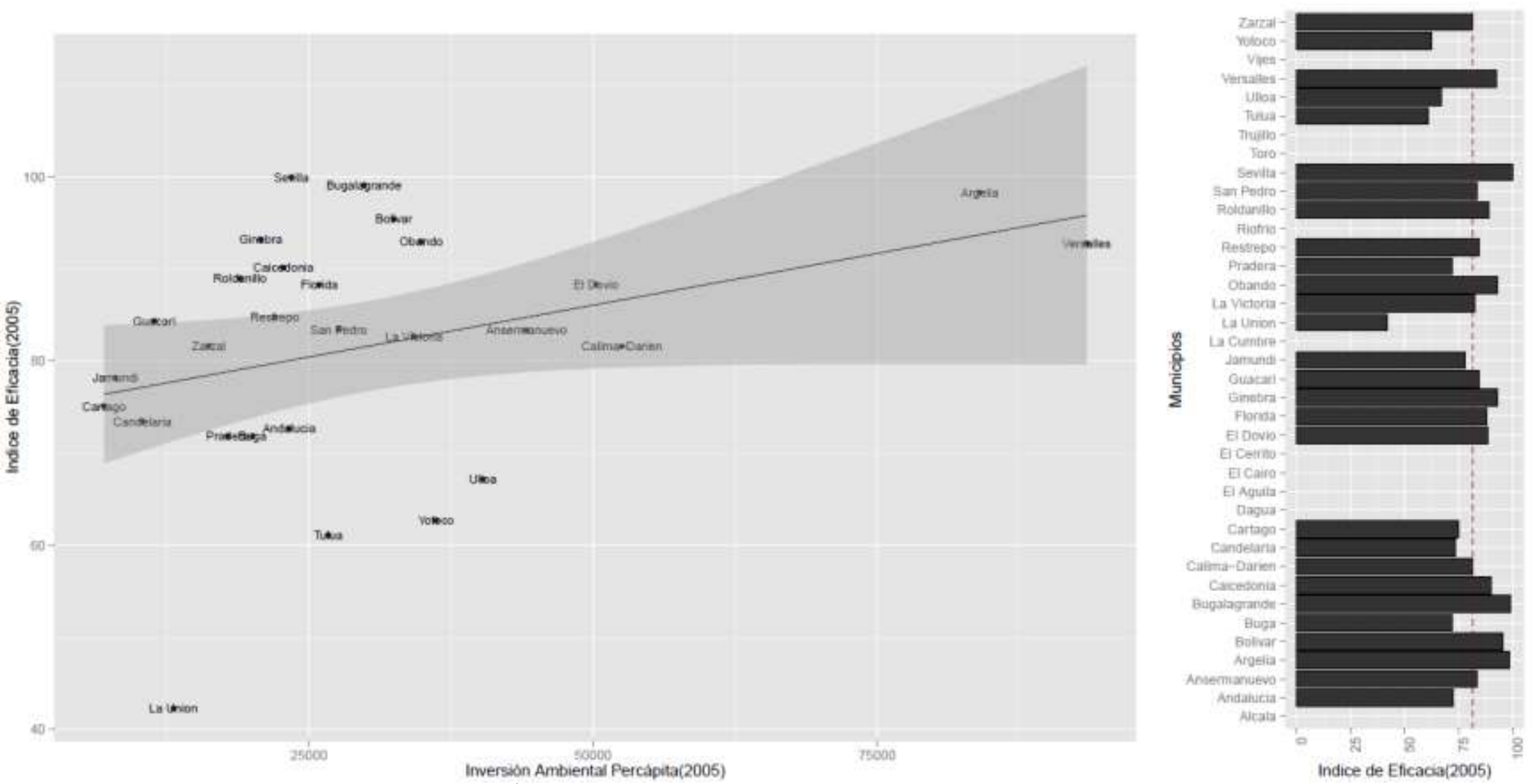

Anexo 3. Inversión Ambiental Municipal Per-Cápita vs Índice de Eficacia de la Gestión Municipal en los Municipios del Valle del Cauca. Fuente: Elaboración propia con base en la Contraloría Departamental del Valle del Cauca- Federación Colombiana de Municipios. 


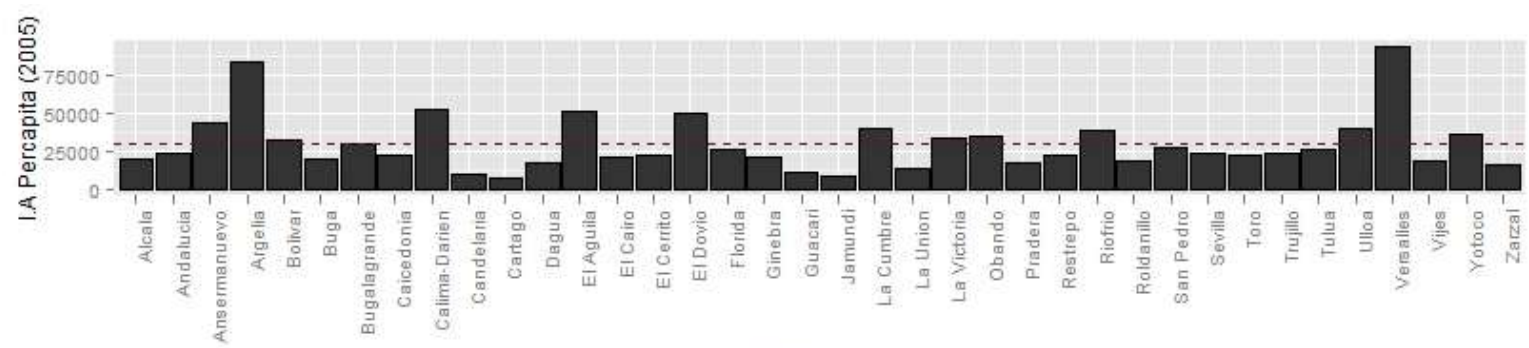

Municipios
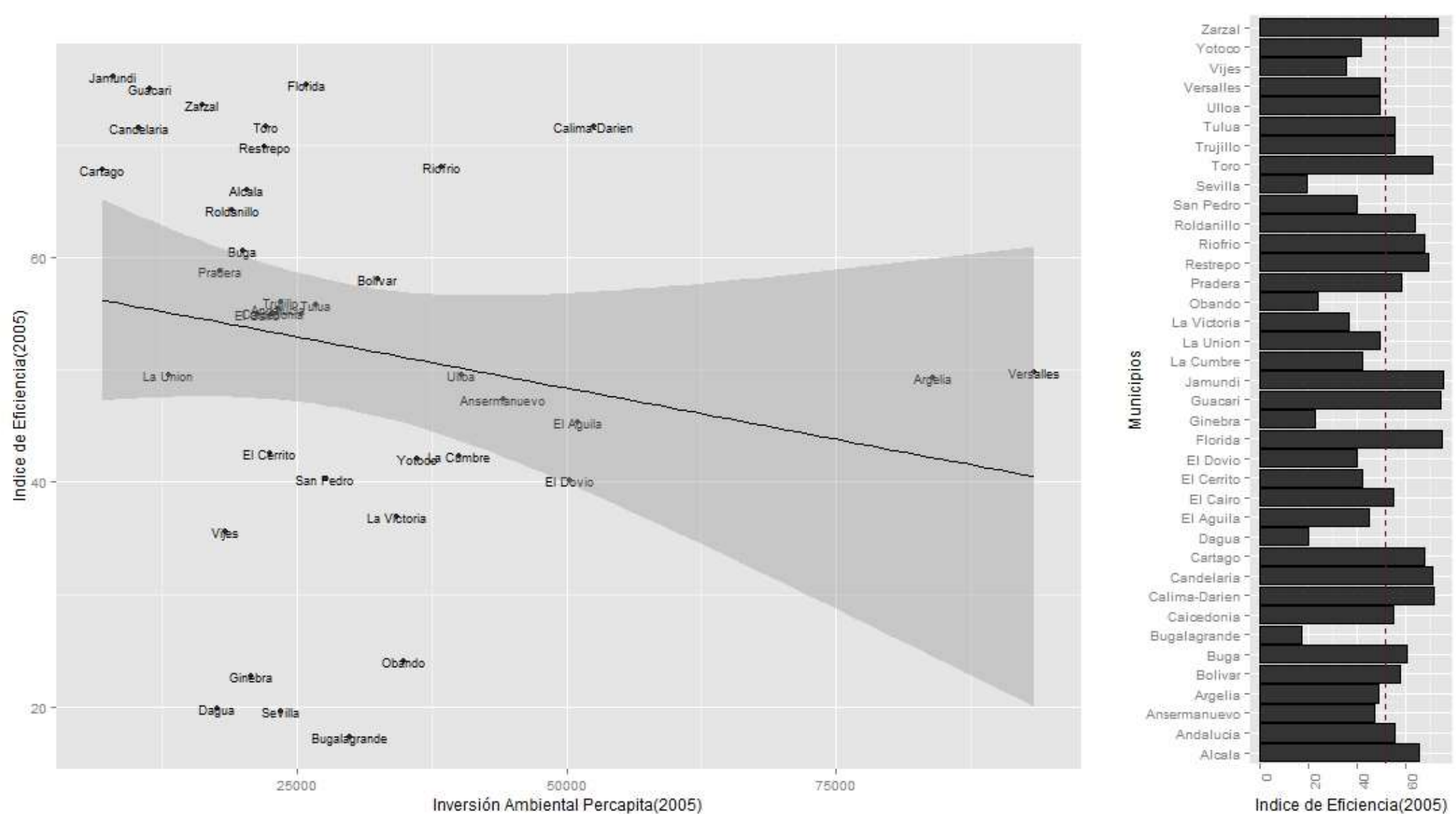

Anexo 4. Inversión Ambiental Municipal Per-Cápita vs Índice de Eficiencia de la Gestión Municipal en los Municipios del Valle del Cauca. Fuente: Elaboración propia con base en la Contraloría Departamental del Valle del Cauca- Federación Colombiana de Municipios. 


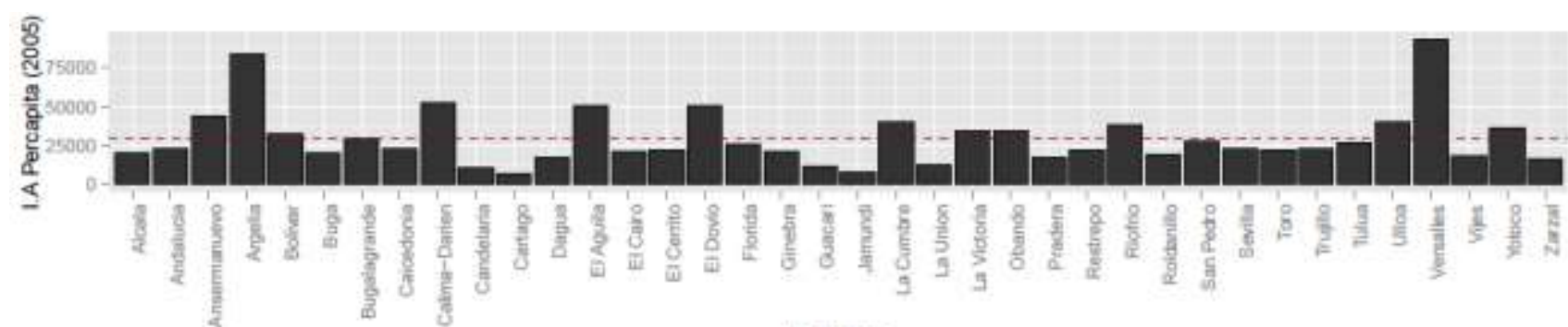

Municipios
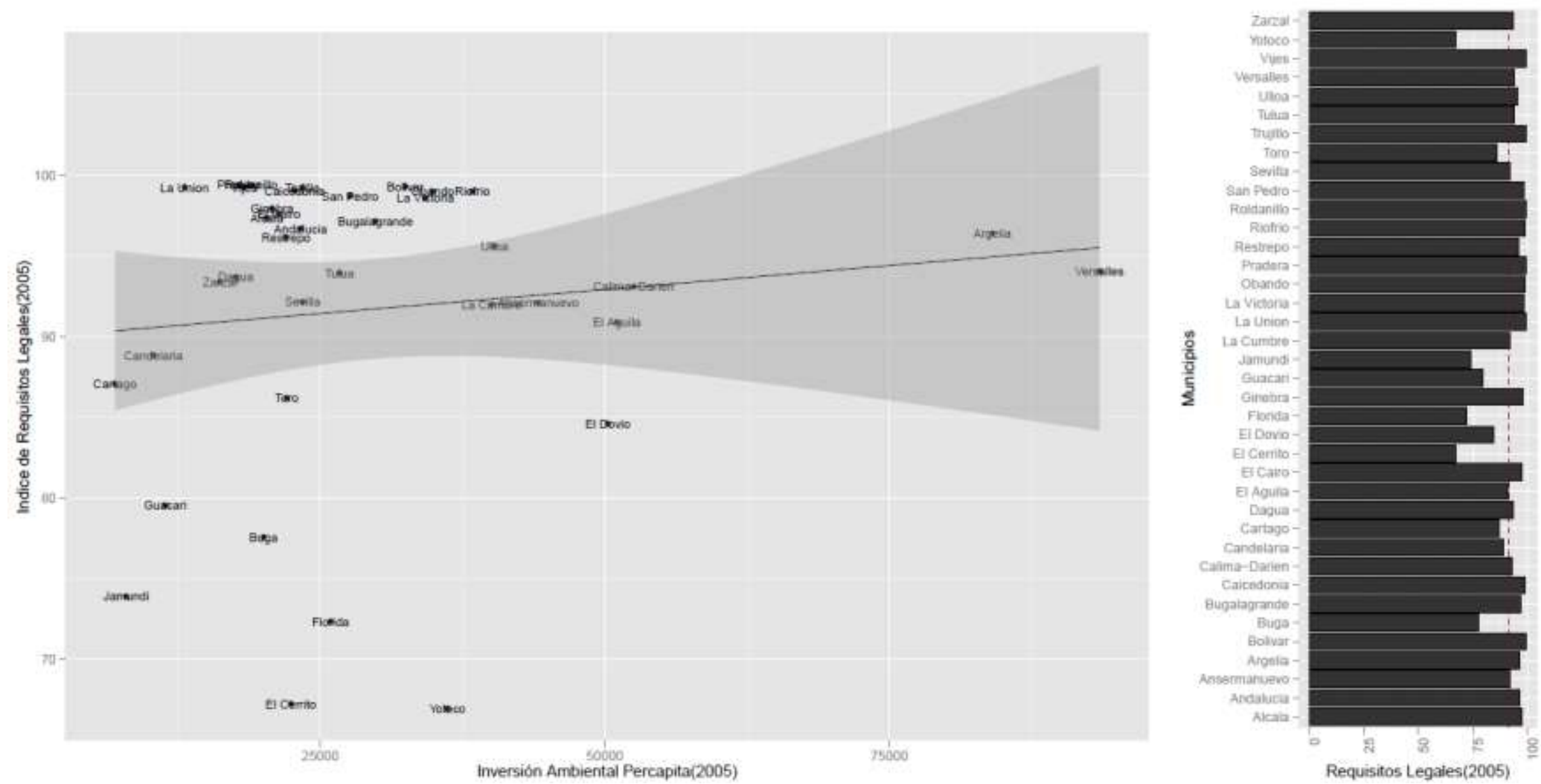

Anexo 5. Inversión Ambiental Municipal Per-Cápita vs Índice de Requisitos Legales de la Gestión Municipal en los Municipios del Valle del Cauca. Fuente: Elaboración propia con base en la Contraloría Departamental del Valle del Cauca- Federación Colombiana de Municipios. 


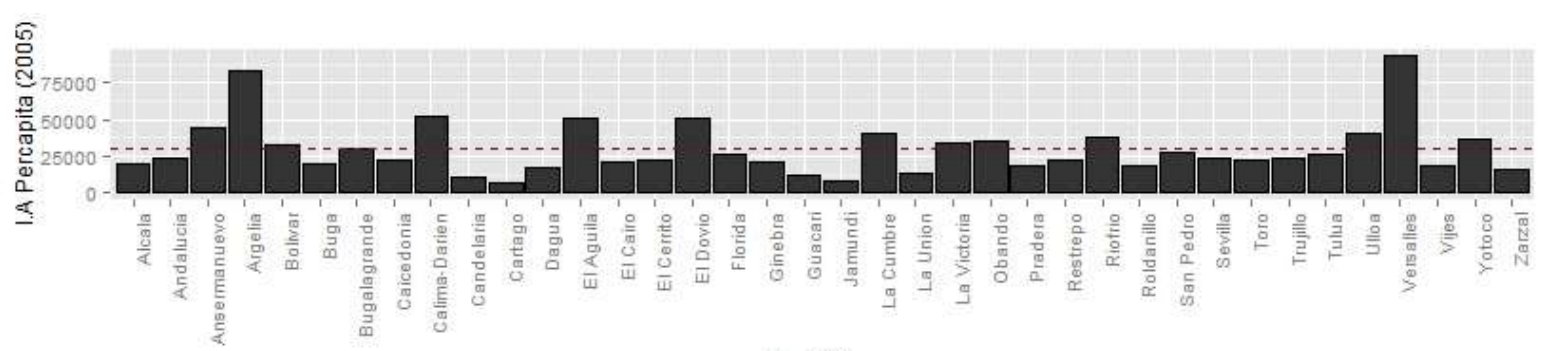

Municipios
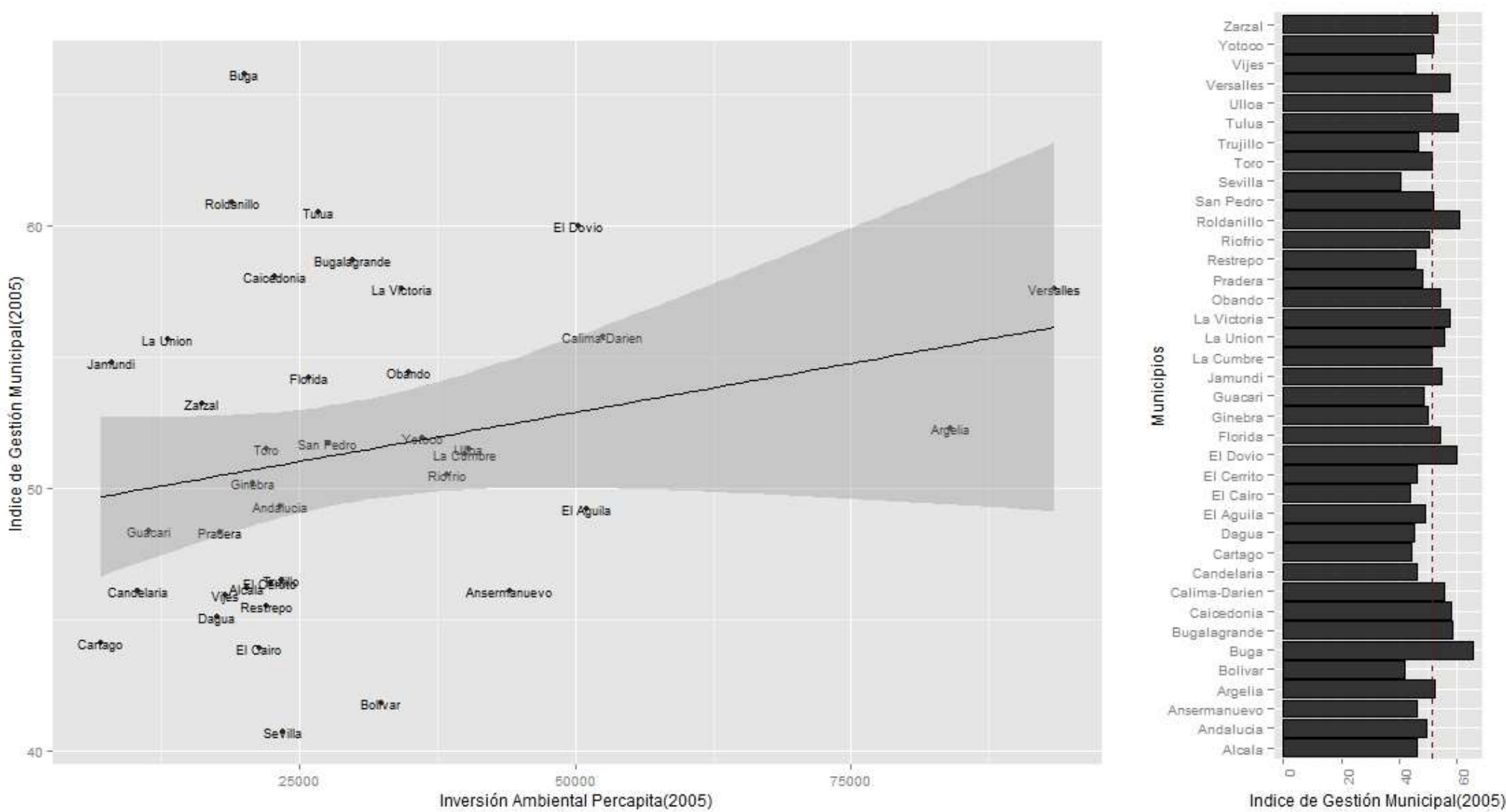

Anexo 6. Inversión Ambiental Municipal Per-Cápita vs Gestión Municipal en los Municipios del Valle del Cauca. Fuente: Elaboración propia con base en la Contraloría Departamental del Valle del Cauca- Federación Colombiana de Municipios. 
Ambiente y Sostenibilidad 2015 (5): 78-96

Revista del Doctorado Interinstitucional en Ciencias Ambientales

ISSN: 2339-3122

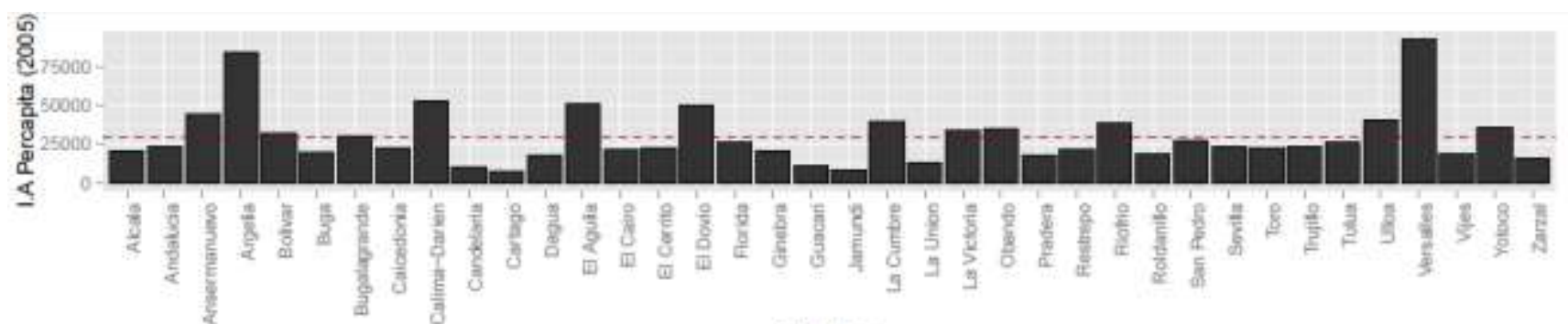

Municipios
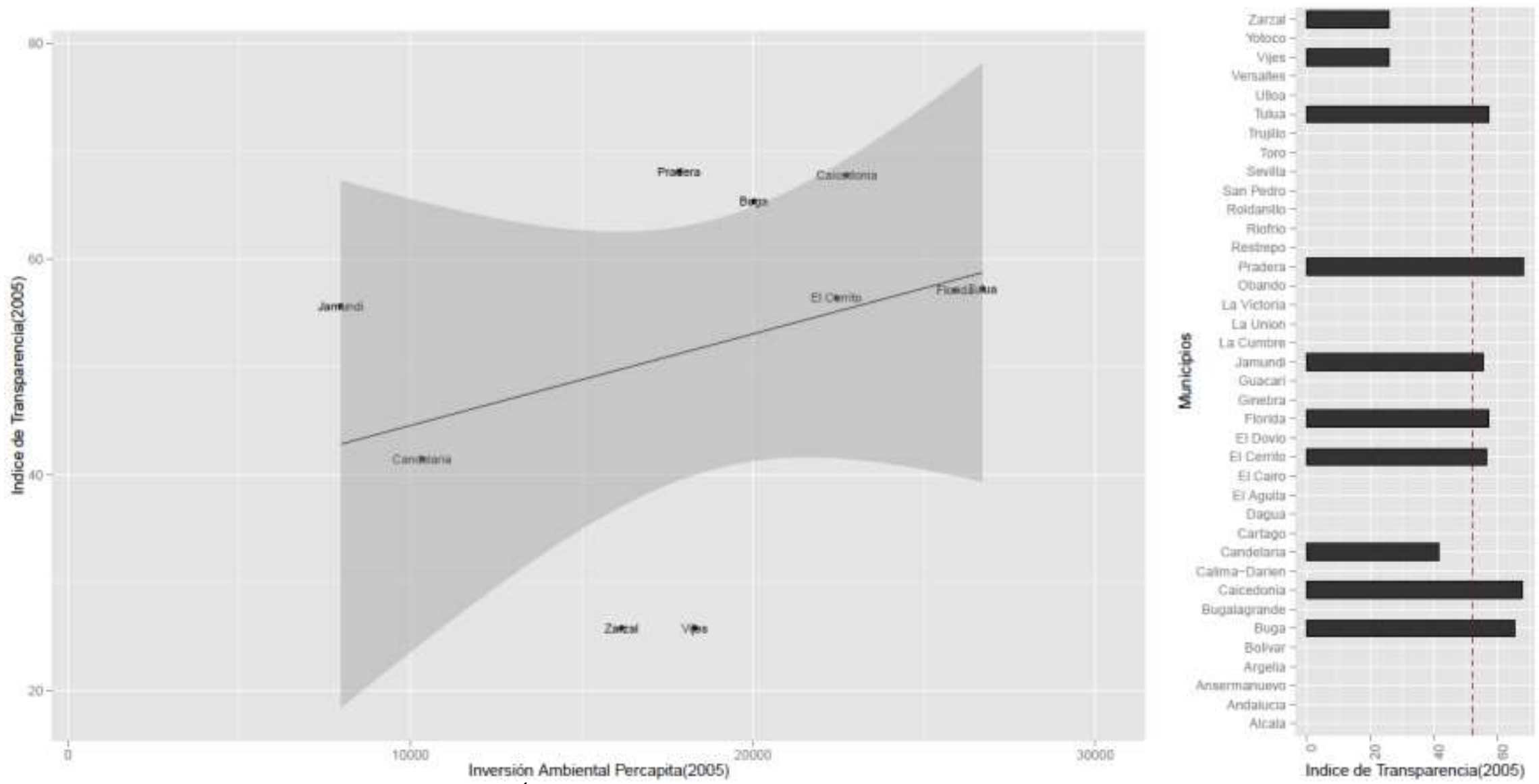

Anexo 7. Inversión Ambiental Municipal Per-Cápita vs Índice de Transparencia Municipal en los Municipios del Valle del Cauca. Fuente: Elaboración propia con base en la Contraloría Departamental del Valle del Cauca- Federación Colombiana de Municipios. 